\title{
Abrasion properties of self-suspended hairy titanium dioxide nanomaterials
}

\author{
Jiao-xia Zhang ${ }^{1} \cdot \mathrm{Si} \mathrm{Liu}^{1} \cdot$ Chao Yan $^{1}$ (D) Xiao-jing Wang ${ }^{1}$ Lei Wang ${ }^{1} \cdot$ \\ Ya-ming $\mathrm{Yu}^{2} \cdot$ Shi-yun $\mathrm{Li}^{1}$
}

Received: 16 July 2017/ Accepted: 22 September 2017/Published online: 5 October 2017

(c) The Author(s) 2017. This article is an open access publication

\begin{abstract}
Considering the excellent solubility of pyrrolidone ring organic compounds, the synthesized $\mathrm{N}$ (trimethoxysilyl) propyl- $N$-methyl-2-pyrrolidone chlorides was tethered onto titanium dioxide $\left(\mathrm{TiO}_{2}\right)$ nanoparticles to improve dispersion of $\mathrm{TiO}_{2}$, and then polyethylene oxide (PEO) oligomer through ion exchange embraced the tethered $\mathrm{TiO}_{2}$ to obtain a novel self-suspended hairy $\mathrm{TiO}_{2}$ nanomaterials without any solvent. A variety of techniques were carried out to illustrate the structure and properties of the self-suspended hairy $\mathrm{TiO}_{2}$ nanomaterials. It was found that $\mathrm{TiO}_{2}$ nanoparticles embody monodispersity in the hybrid system though the "false reunion" phenomenon occurring due to nonpermanent weak physical cross-linking. Remarkably, self-suspended hairy $\mathrm{TiO}_{2}$ nanomaterials exhibit lower viscosity, facilitating maneuverable and outstanding antifriction and wear resistance properties, due to the synergistic lubricating effect between spontaneously forming lubricating film and nano-lubrication of $\mathrm{TiO}_{2}$ cores, overcoming the deficiency of both solid and liquid lubricants. This make them promising candidates for the micro-electromechanic/nano-electromechanic systems (MEMS/NEMS).
\end{abstract}

Keywords Friction and wear properties - Self-suspended hairy nanomaterials $\cdot \mathrm{TiO}_{2}$ nanoparticles $\cdot$ Liquid-like behavior

Chao Yan

chaoyan@just.edu.cn

1 School of Materials Science and Engineering, Jiangsu University of Science and Technology, Zhenjiang 212003, China

2 College of Materials Science and Engineering, Huaqiao University, 361021 Xiamen, China

\section{Introduction}

With the rapid development of nanotechnology, the moving interface gap of micro-/nano-electromechanical systems and magnetic recording system has been reduced to nanometers for achieving more components on per unit, faster response speed and better and more properties. Therefore, nanotribology puts forward higher requirements such as high thermal stability, excellent temperature fluidity, low vapor pressure, good lubrication, abrasion-resistance and self-repairing capacity (Rojas et al. 2015; Ye et al. 2001; Hussein et al. 2015; Tang et al. 2014). Solid inorganic or liquid organic materials are the traditional lubricants for controlling friction and wear, e.g., natural and synthetic organics (animal fat, vegetable oil, refined oil, silicone oil, esters, etc.), micro-/nanometal oxide powder $\left(\mathrm{MoS}_{2}, \mathrm{ZnO}\right.$, etc. $)$ and carbon materials. In general, solid lubricants are usually added into the lube base oil to reduce the interfacial friction and improve the load-bearing capacity of the parts by their benign extreme pressure grease, anti-oxide, anti-wear roles and so on. However, solid lubricating additives cannot homogeneously disperse well in the base oil, due to their easy agglomeration and poor compatibility with the base oil. Compared with the solid lubricants, liquid lubricants show different advantages, such as long-term endurance, low mechanical noise, promotion of thermal conductance and very low friction in the elastohydrodynamic film regime (Zheng et al. 2016). Liquid lubricants can be directly used as lubricant without the base oil, but their ability to bear the wear resistance decreases due to the absence of solid nanoparticles (Guo et al. 2006).

Compared with traditional nanofluids, novel self-suspended nanomaterials at room temperature through covalent graft a soft organic corona onto the nanomaterials 
surface have been proved to enhance the manipulation and impart compatibility of nanoparticles (Huang et al. 2016; Li et al. 2015; Lei et al. 2008; Zheng et al. 2016; Warren et al. 2006). Organic corona generally refers to a surfaceactive agent, in which one end can tether nanoparticles and the other can further bond with polymers. A series of selfsuspended hairy nanomaterials based on various nanoparticles such as $\mathrm{TiO}_{2}, \mathrm{SiO}_{2}$, graphene oxide and carbon nanotubes have been fabricated using nanoparticles as cores, surface functionalized with a charged corona, and ionically tethered with oligomeric chains as a canopy to balance the charge (Zhang et al. 2009a, b, 2013; Yang et al. 2016c; Petit et al. 2013; Li et al. 2009, 2016a, b). Selfsuspended hairy nanomaterials offer attractive possibilities for particular applications, e.g., transportation, microelectromechanical systems (MEMS), liquid electrolytes and magnetic fluid. For the lubricating materials, silicabased nanomaterials with liquid-like behavior used as thickeners in traditional lubricating oils created lubricants whose friction coefficients were lower than that of the base oil, as demonstrated by Yang et al. (2016b) and Kim and Archer (2011). More importantly, wear resistance also was reduced due to the localization of silica in the wear tracks of the contact surface. The silica-based nanomaterial with liquid-like ( $\mathrm{Li}$ et al. 2016a, b; Bai et al. 2016) behavior described here is one of the ideal lubricating systems that successfully combines the advantages and efficiently avoids deficiency of both solid and liquid lubricants.

However, nanoparticles exhibit stable performance, and the random accumulation in the whole system makes it difficult to form a film. Long-chain organic matter can easily form regular and orderly molecular film, but the poor thermal stability and mechanical stability restrain their application in the tribology field. For the self-suspended hairy $\mathrm{TiO}_{2}$ nanomaterials, we consider their synergies: nanoparticles can not only form nanoscale lubricating film on the surface of the friction pair, but also repair the wear surface through a scrollable sliding bearing role. The long-chain ionic liquids display a much higher molecular weight and flexible and stronger binding force with substrate, facilitating the formation of a viscous lubricating film. So, it is a beneficial challenge to develop some new lubricating materials. It is believed that self-suspended hairy nanomaterials may obtain the same or even better effects when directly used as lubricants without the base oil. So, it is believed that self-suspended hairy nanomaterials may obtain the same or even better effects when directly used as lubricants without the base oil. In the present experiment, in view of the low toxicity and excellent solubility of the pyrrolidone ring organic compounds, known as "super solvent" (Giordani et al. 2006), we first synthesized the alkyl pyrrolidone ring taskspecific ionic liquids with excellent solubility and surface activity as the corona to modify the dispersibility of nanoparticles. Then, the counterion long-chain organic corona was introduced to obtain self-suspended hairy $\mathrm{TiO}_{2}$ nanomaterials with a core-corona-canopy structure using the ion exchange reaction. We studied their abrasion properties of self-suspended hairy $\mathrm{TiO}_{2}$ nanomaterials against the slide, which showed good friction reduction and anti-wear capacity.

\section{Results and discussion}

\section{Preparation of self-suspended hairy $\mathrm{TiO}_{2}$ nanomaterials}

First, anatase $\mathrm{TiO}_{2}$ nanoparticles with a large number of hydroxyl groups were prepared by the sol-gel method. Then, self-suspended hairy $\mathrm{TiO}_{2}$ nanomaterials were prepared through a simple and facile two-step method as shown in Fig. 1. Synthetic functionalized ionic liquids were heated and reacted with $\mathrm{TiO}_{2}$ nanoparticles (Guo et al. 2009). Based on the chemical bonding theory, the synthetic functionalized ionic liquids contain two different chemical functional groups, of which one can react with silanol groups on the surface of the inorganic material (such as metal oxides, inorganic salts, glass fibers, silicates) and the other can further participate in other reactions, so that the two kinds of materials with very different properties can be "coupled" together. Based on Arkles theory, the process consisted of a four-step reaction (Arkles 1977). The specific reaction mechanism is shown in Fig. 1.

The charged oligomer weakens the short-range attraction among adjacent $\mathrm{TiO}_{2}$ nanoparticles through a steric effect (Zhang et al. 2009a, b). In addition, the charged oligomer decreases the surface free energy of nanoparticles, and the electrostatic interactions among anionic $\mathrm{TiO}_{2}$ colloids effectively improve the dispersion of $\mathrm{TiO}_{2}$ nanoparticles. In the second step, organic sulfonate implements the ion exchange and self-assembly (Langford and Stoddart 1996; Philp and Stoddart 1996) reaction with fatty alcohol polyoxyethylene ether sulfonate $\mathrm{C}_{9} \mathrm{H}_{19}$ $\mathrm{C}_{6} \mathrm{H}_{4}-\left(\mathrm{OCH}_{2} \mathrm{CH}_{2}\right)_{20}\left(\mathrm{CH}_{2}\right)_{3} \mathrm{SO}^{3-} \mathrm{K}^{+}$(FAPES).

In self-suspended hairy nanomaterials system, organic sulfonate as canopy provides enough "solvent" for the dispersion of the $\mathrm{TiO}_{2}$ nanoparticles. The organic shell acts like a lubricant among the core nanoparticles.

\section{Chemical and physical performances of self- suspended hairy $\mathrm{TiO}_{2}$ nanomaterials}

The chemical structures of primary materials and selfsuspended hairy $\mathrm{TiO}_{2}$ nanomaterials are shown in Fig. 2. 


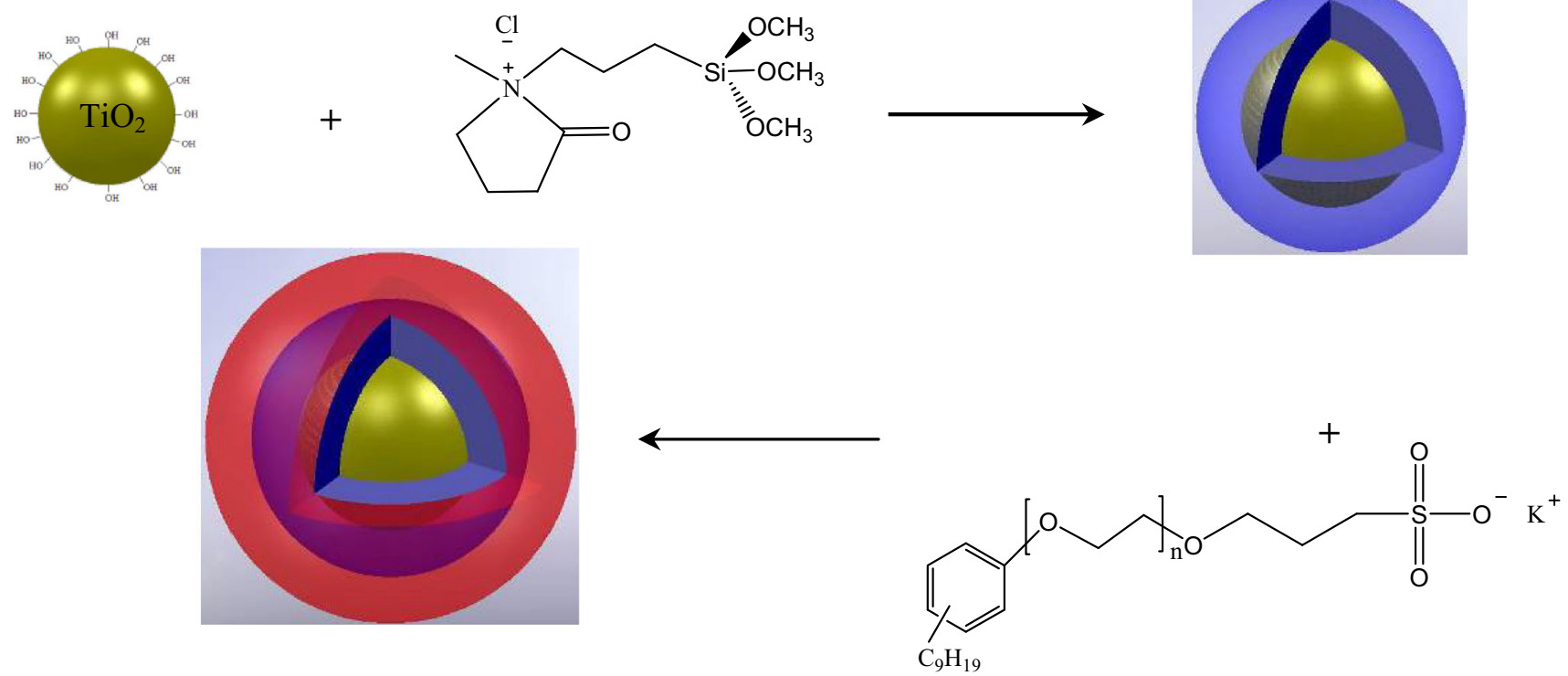

Fig. 1 The scheme of self-suspended hairy $\mathrm{TiO}_{2}$ nanomaterials

$\mathrm{TiO}_{2}$ nanomaterials show $\mathrm{S}=\mathrm{O}$ stretching vibration absorption peak at about $1200 \mathrm{~cm}^{-1}$, while many small peaks appearing in the fingerprint region are caused by the pyrrole ring of functionalized ionic liquids. Clearly, the

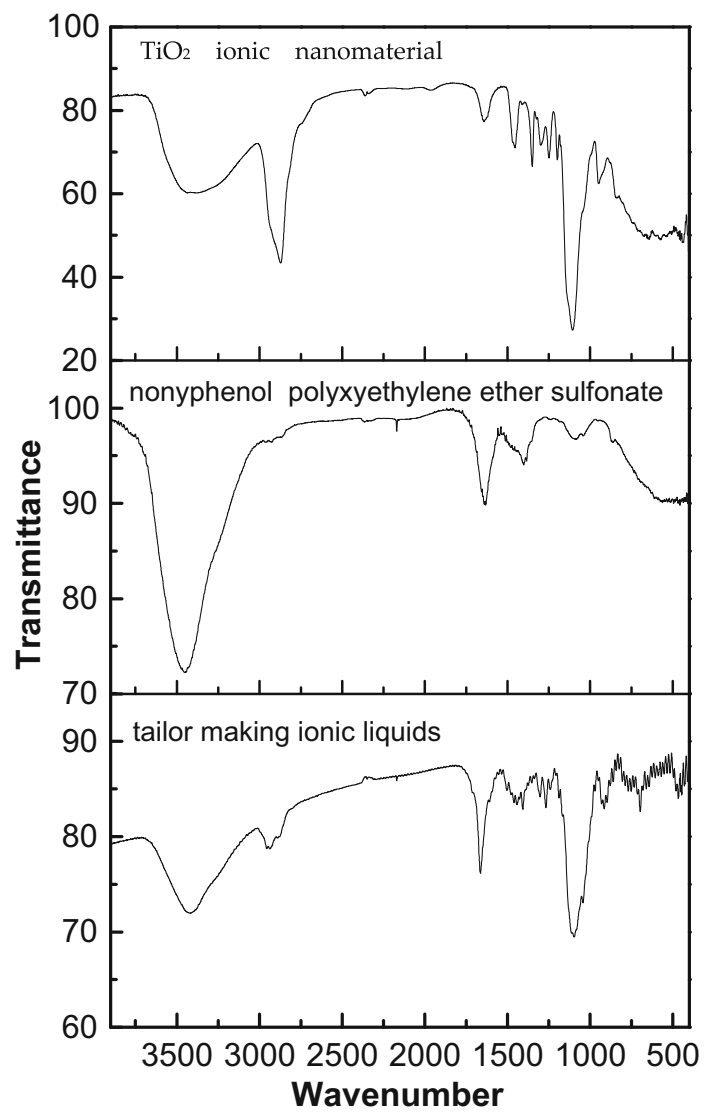

Fig. 2 FTIR spectra for $\mathrm{TiO}_{2}$ ionic nanomaterial functionalized ionic liquids and nonylphenol polyoxyethylene sulfonate are grafted successfully on the surface of $\mathrm{TiO}_{2}$ nanoparticles.

Figure 3a shows the TEM images of self-suspended hairy $\mathrm{TiO}_{2}$ nanomaterials, which displayed different morphologies at different conditions. For the sample in Fig. 3a, an appropriate amount of water was directly added to small amounts of the sample. The resulting solution was dispersed ultrasonically for $30 \mathrm{~min}$, then directly dropped on a copper grid and the water evaporated. The TEM image in Fig. $3 \mathrm{~b}$ was taken by dispersing the liquid in water $(5 \%$ $\mathrm{w} / \mathrm{v}$ ), heating and ultrasonic dispersing at $60{ }^{\circ} \mathrm{C}$ for $5 \mathrm{~min}$, then placing a few drops of the dispersion on a copper grid and evaporating the water. Figure $3 \mathrm{a}$ reveals that partial nanoparticles emerge with flocculation and are bonded together at room temperature (under $20^{\circ} \mathrm{C}$ ). Organic molecular chain segment on the surface of the nanoparticles move difficultly under melting transition temperature according to the DSC curves (see Fig. 5). The interaction among organic molecules forms a nonpermanent weak physical cross-linking (associative phenomena) and leads to the "false reunion" phenomenon (Wang 2008).

When heating, the temperature is high than the melting transition temperature, Brownian motion of particles accelerate, organic molecular chains grafted on the surface move freely and the segments are stretched. Then the nanoparticles overcome the interaction force and realize monodisperse after ultrasonic dispersion. The nanomaterials were heated at $60{ }^{\circ} \mathrm{C}$ for $5 \mathrm{~min}$, the false reunion phenomenon disappeared and the $\mathrm{TiO}_{2}$ nanoparticles showed monodispersity, as in Fig. 3b. After the heating treatment, it can also be seen from Fig. $3 \mathrm{~b}$ that $\mathrm{TiO}_{2}$ 

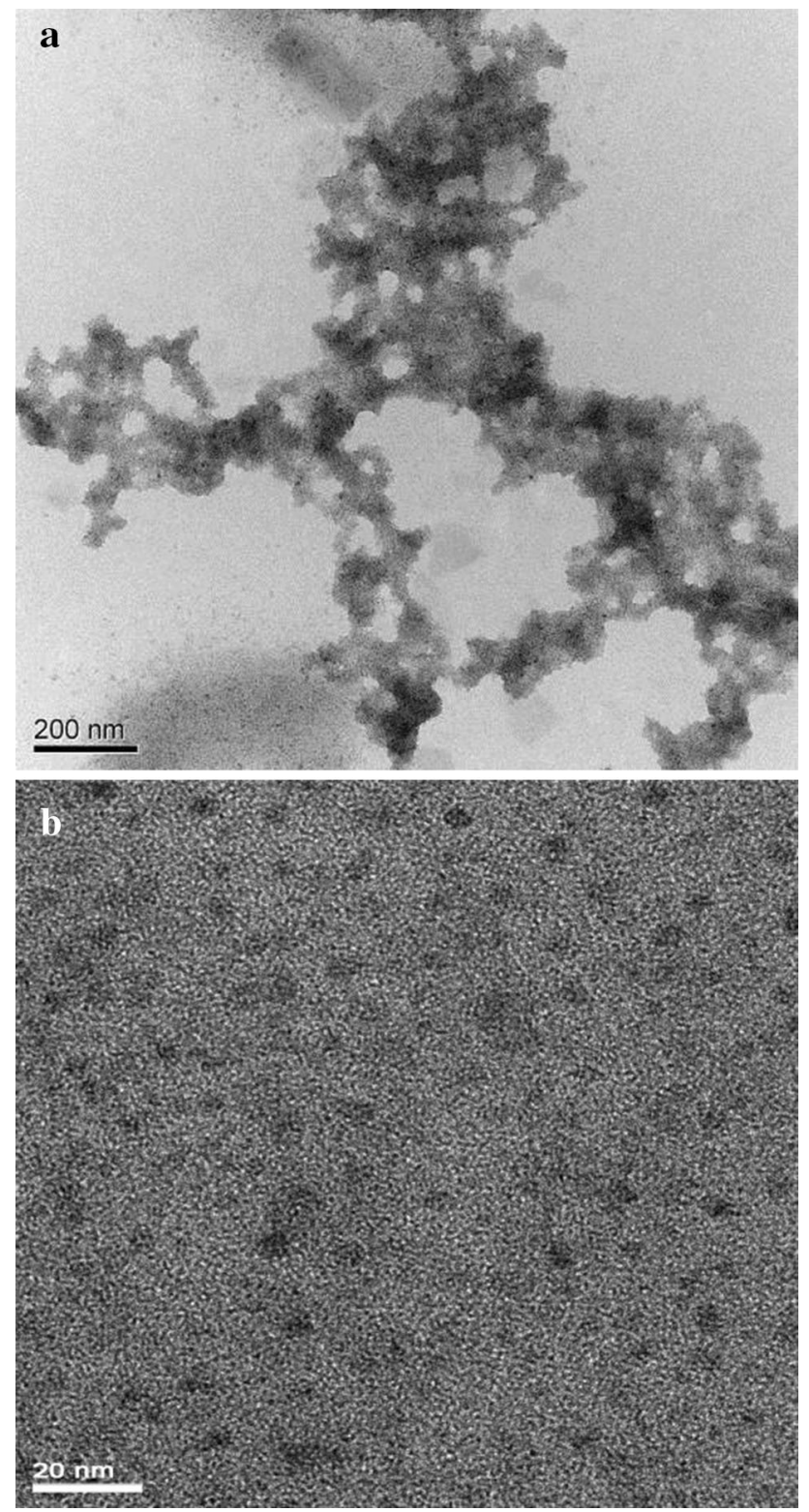

Fig. 3 TEM images of $\mathrm{TiO}_{2}$ ionic nanomaterial. The sample was prepared, $\mathbf{a}$ at room temperature and $\mathbf{b}$ heating at $60{ }^{\circ} \mathrm{C}$

nanoparticles exhibit monodispersed distribution in size with a diameter of about $4 \mathrm{~nm}$, which illustrates that functionalized ionic liquids graft on the surface of nanoparticles through covalent bonds promote the monodispersity. Self-suspended hairy nanomaterials are composed of nanoparticles and ionic species canopy by $\mathrm{Si}-$ $\mathrm{O}-\mathrm{C}$ chemisorption and electrical role. The dense corona brush effectively reduces the surface energy of the nanoparticles and stabilizes the nanoparticles against aggregation. At the same time, functionalized ionic liquids contain $\mathrm{N}$-methyl-2-pyrrolidone structure, which is known as a "super solvent". Carbon nanotubes are almost insoluble in all solvents, but exhibit good dispersity in $\mathrm{N}$ -

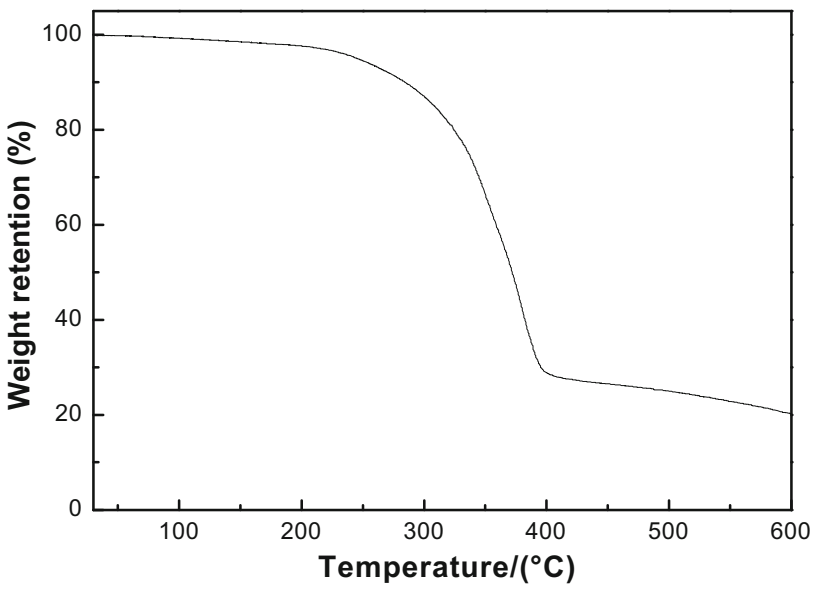

Fig. 4 TGA curve of self-suspended hairy $\mathrm{TiO}_{2}$ nanomaterials

methyl-2-pyrrolidone, which was reported by Giordani et al., and the calculation showed that the enthalpy change of the mixture, which consists of carbon nanotubes solute and $\mathrm{N}$-methyl-2-pyrrolidone solvent, is negative and the mixture is a kind of true solution (Giordani et al. 2006). Carbon nanotubes dissolve in the "super solvent" $\mathrm{N}$ methyl-2-pyrrolidone ( $\mathrm{Li}$ et al. 2012). Therefore, $\mathrm{N}$ methyl-2-pyrrolidone in the present system can further increase the solubility of $\mathrm{TiO}_{2}$ nanoparticles in ionic liquids, thereby enhance the dispersity of ionic nanomaterials (Guo et al. 2006).

The content of organic canopy on the surface of nanoparticles (Yu et al. 2016) influenced the properties of self-suspended hairy nanomaterials. Thermogravimetric analysis (TGA) is a simple way to quantify the organic content of $\mathrm{TiO}_{2}$ ionic nanomaterial. There is almost no thermal weight loss within the low temperature range as shown in Fig. 4, which suggests that few solvent or residual small molecules were involved in the $\mathrm{TiO}_{2}$ ionic nanomaterial. The weight loss above $200{ }^{\circ} \mathrm{C}$ is attributed to decomposition of the organic sulfonate groups. $\mathrm{The}^{\mathrm{TiO}_{2}}$ content is around $20 \mathrm{wt} \%$, which can increase the thermal stability of the organic canopy.

Figure 5 presents the DSC curves of $\mathrm{TiO}_{2}$ ionic nanomaterial and nonylphenol polyoxyethylene ether sulfonate. The sample was heated to $120{ }^{\circ} \mathrm{C}$ and cooled down to $-40{ }^{\circ} \mathrm{C}$; then the reheating process was recorded. Figure 5 a shows that pure nonylphenol polyoxyethylene ether sulfonate manifests a crystallization transition at $T_{\mathrm{c}} \approx-14^{\circ} \mathrm{C}$, and a melting transition at a temperature $T_{\mathrm{m}} \approx 27^{\circ} \mathrm{C}$. Nonylphenol polyoxyethylene ether sulfonate also exhibits a metastable phase with melting temperature around $12{ }^{\circ} \mathrm{C}$. The curve of $\mathrm{TiO}_{2}$ ionic nanomaterial (Fig. 5b) is similar to that of nonylphenol polyoxyethylene ether sulfonate, but all of the characteristic peaks are found at lower temperature. It appears the 


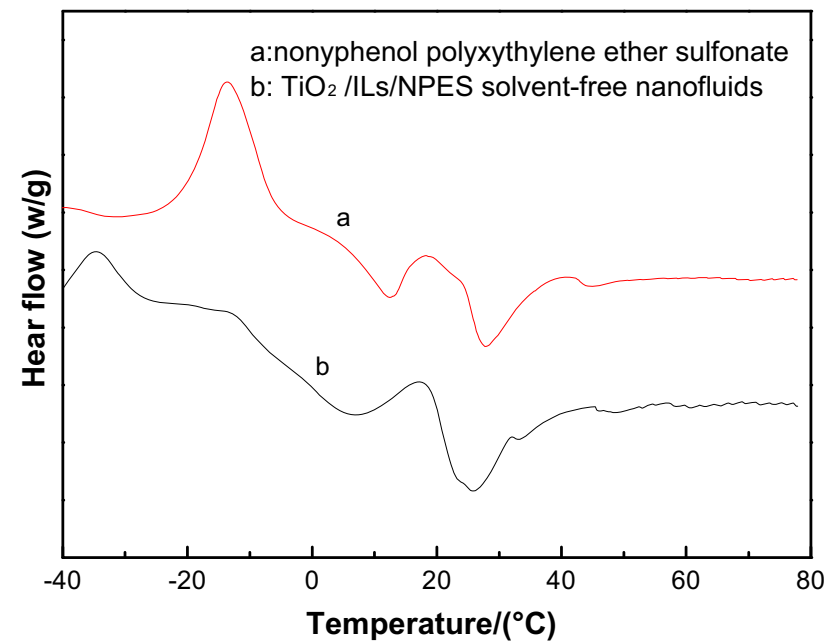

Fig. 5 DSC curves of self-suspended hairy $\mathrm{TiO}_{2}$ nanomaterials

corresponding temperatures are at $-34,6$, and $25^{\circ} \mathrm{C}$, respectively. The $\mathrm{TiO}_{2}$ nanoparticles may be used as the nucleating agent promoting the organic modifier to cause crystallization transition. However, the connection between nanoparticles and the organic modifier hinders the free rearrangement of the organic modifier during the crystallization process and results in lower melting temperature.

The effect of physical state on the transport and stability is critical to design the lubricant. Self-suspended hairy $\mathrm{TiO}_{2}$ nanomaterials display a wine-red transparent liquid-like appearance with no evident phase separation in the absence of the solvent at room temperature (insert of Fig. 6a). The wine-red transparence and high fluidity are attributed to the "super solvent" ionic liquids covalently grafting onto $\mathrm{TiO}_{2}$ and the high content of organic canopy acting like a solvent of the inorganic cores. To understand the rheological behavior, the rheometer was further performed under two types of the steady rotate flow (Fig. 6a, b) and small-amplitude oscillatory flow (Fig. 6c). The shear viscosity is basically independent of the shear rate, and the curve of shear stress vs. shear rate diagram is a straight line (see Fig. 6a). It indicates Newtonian fluid behavior for self-suspended hairy $\mathrm{TiO}_{2}$ nanomaterials with a constant shear viscosity covering a wide range of shear rates $\left(0.1-100 \mathrm{~s}^{-1}\right)$ (Fig. 6a). The viscoelastic behavior in our work is consistent with the report of tertiary amine-based silica ionic nanomaterials reported by Gu et al. (2013). However, the Newtonian plateau with shear thinning appears in the lowest shear rate region due to the minimum shear rate threshold value of our rheometer used. Over a temperature range $\left(20-80{ }^{\circ} \mathrm{C}\right)$, it can be recognized from the rheological traces (Fig. 6b) that the storage modulus and loss modulus decrease with the temperature increases. Because temperature enhances the molecular movement, the extension and retraction of
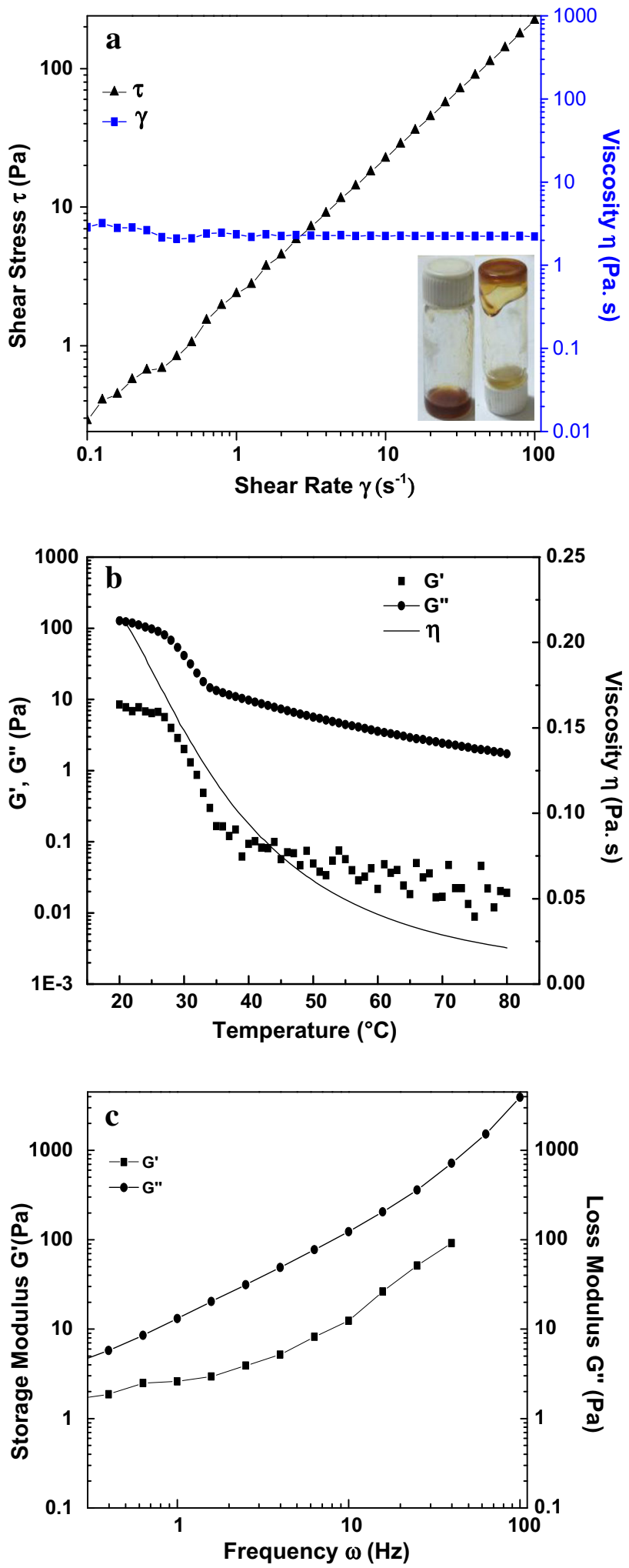

Fig. 6 Shear viscosity vs. shear rate a, photo images (insert of a), and rheological behavior vs. temperature (b) at steady rotate mode and $\mathrm{G}^{\prime}$, $\mathrm{G}^{\prime \prime}$ vs. frequency at oscillatory dynamic mode (c) for self-suspended hairy $\mathrm{TiO}_{2}$ nanomaterials 
chain segments become easier and the times of collision between segments increase. Evidently, temperature can regulate their fluidity. It is further confirmed by the viscosity-temperature relationship. It can be seen that the viscosity of nanomaterials is $0.2 \mathrm{~Pa} \mathrm{~s}$ at $20^{\circ} \mathrm{C}$, while it decreases rapidly to $0.02 \mathrm{~Pa} \mathrm{~s}$ when the temperature increases to $80{ }^{\circ} \mathrm{C}$. The viscosity of self-suspended hairy nanomaterials is between water and glycerol 0.001 and $1.50 \mathrm{~Pa} \mathrm{~s}$ at $20^{\circ} \mathrm{C}$, respectively. $\mathrm{TiO}_{2}$ nanomaterials exhibit lower viscosity than that of $\mathrm{TiO}_{2} / \mathrm{TSAC} / \mathrm{NPES}$ and $\mathrm{TiO}_{2} / \mathrm{DMAC} / \mathrm{NPES}$ (Yang et al. 2016a; Tan 2013). Low viscosity is attributed to the structure of the canopy, which contains "super solvent" in the functionalized ionic liquid and without branches. The frequency-dependent dynamic elastic modulus was recorded in the linear viscoelastic region with angular frequencies ranging from 0.1 to $100 \mathrm{rad} \mathrm{s}^{-1}$ and a constant strain value of $1 \%$. The loss modulus exceeds the storage modulus over the whole measured frequency (Fig. 6c), indicating a liquid-like behavior of self-suspended hairy $\mathrm{TiO}_{2}$ nanomaterials under those conditions. The liquid-like behavior of selfsuspended hairy $\mathrm{TiO}_{2}$ nanomaterials without solvent originated from the ionic bonding structure and ion exchange (Tang et al. 2012), where the former promotes the monodipersibility of $\mathrm{TiO}_{2}$ and the latter provides an organic canopy moving on and off the $\mathrm{TiO}_{2}$ core.

\section{Tribological properties of self-suspended hairy $\mathrm{TiO}_{2}$ nanomaterials}

Nanoparticles can reduce the resistance in the friction process by a similar "micro bearing" effect. Nanoparticles can form a smooth protective layer of friction pairs, and fill the crater and damage the surface of friction pairs. This plays an important role in lubrication and surface repair. Organic polymers having a higher molecular weight, good flexibility, and strong adhesion to the substrate can lubricate friction pairs by a viscous thin film. Therefore, the organic-inorganic hybrid nanomaterials can effectively improve the tribological properties of the material. Nanotribological behaviors of the self-suspended hairy $\mathrm{TiO}_{2}$ nanomaterials were investigated by a friction and wear tester in the present work. The friction coefficients under different applied normal loads are shown in Fig. 7. The value of the friction coefficient on the silica substrate rapidly increases within $80 \mathrm{~s}$ and then become relatively stable. While $10 \mathrm{wt} \%$ of ion nanomaterials is spread over the silica substrate, the friction coefficient display essentially unchanged as test time go on. Table 1 shows that the average friction coefficient decreases as the load increases. This is mainly because the surface convex peaks on the real contact parts of the friction surface were pressed and meshed with each other under a large unit pressure.

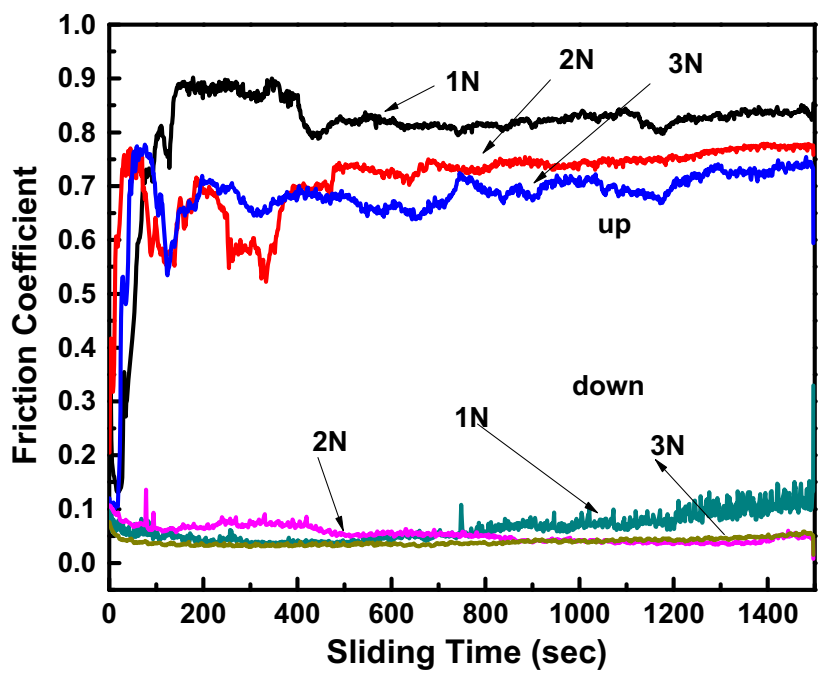

Fig. 7 The friction coefficient curve of self-suspended hairy $\mathrm{TiO}_{2}$ nanomaterials (up: silica substrate, down: $10 \mathrm{wt} \%$ nanomaterials on the silica substrate)

Table 1 The average friction coefficient of self-suspended hairy $\mathrm{TiO}_{2}$ nanomaterials

\begin{tabular}{lll}
\hline \multirow{2}{*}{ Loads } & \multicolumn{2}{l}{ Average friction coefficient } \\
\cline { 2 - 3 } & Silica substrate & $10 \mathrm{wt} \%$ nanomaterials \\
\hline $1 \mathrm{~N}$ & 0.81 & 0.06 \\
$2 \mathrm{~N}$ & 0.71 & 0.05 \\
$3 \mathrm{~N}$ & 0.68 & 0.04 \\
\hline
\end{tabular}

Meantime, surface molecules also attract each other. Consequently, the friction process is actually a process overcoming the attraction beween mechanical engaging surface molecular of convex peaks on the submicroscopic surface, according to the formula (Huang and Ding 1999):

$f_{\mathrm{m}}=\beta+\gamma \frac{S_{\mathrm{A}}}{N}$,

where $S_{\mathrm{A}}$ is the real contact area, $N$ is the load (positive pressure) and $\beta, \gamma$ are the coefficients, respectively, determined by the physical and mechanical properties of friction surfaces. $\beta$ is a constant and is a friction coefficient based on pure mechanical theory.

For the friction surface, the real contact area increases slowly as the load increases, so the friction coefficient decreases with the increase of the load. In addition, the friction coefficient of self-suspended hairy $\mathrm{TiO}_{2}$ nanomaterials (0.04) is significantly decreased by one order of magnitude less than that of the silica substrate $(0.68)$. This indicates that the self-suspended hairy $\mathrm{TiO}_{2}$ nanomaterial enhances the surface smoothness of the silica substrate, further improves the wear resistance of the material. The 
viscous film on the substrate surface formed by a longchain molecule of hybrid nanomaterials can reduce the shear force between the contact regions and the nanoparticles, which plays a key role during weight bearing. Thus, it can reduce friction and improve the friction and wear properties of the substrate.

To further analyze their friction and wear behavior, we observed microtopographies after washing the coating on silicon substrates. Figure 8 shows the images of scratches under different normal loads. We find that the scratches become wider with the increase of normal loads for the silica substrate. While under the same normal loads, the scratches for ionic nanomaterials are almost invisible. The friction scratches still are invisible on the silica substrate coated with 10 wt\% self-suspended hairy nanomaterials even the magnification enlarging to 1000 times for the sample. The synergistic effect of nanoparticles and oligomer sulfonate enhances wear resistance. We further investigated the scratch surface for silica substrate with and without $10 \mathrm{wt} \%$ nanomaterials under $2 \mathrm{~N}$ load by SEM. Figure 9a, b shows that the silica substrate without nanoparticles had serious wear and obvious scratches, and small cracks similar to fish scales appear on the surface of the silica substrate. The scratches on the silica substrate with 10 wt $\%$ nanomaterials are almost invisible under different magnifications. Table 1 shows that the self-suspended hairy $\mathrm{TiO}_{2}$ nanomaterials are significant on reducing surface friction and improve lubrication performance. The self-suspension $\mathrm{TiO}_{2}$ has high strength and self-lubricant effect and it has an enhancement effect on the surface of the silica substrate. The mechanism of the self-suspended hairy $\mathrm{TiO}_{2}$ nanomaterials is shown in Fig. 10. The self-suspended hairy $\mathrm{TiO}_{2}$ nanomaterials have a ball structure, which makes it possible to produce rolling friction on the friction surface. The surface of this hairy ball material has two layers of polymer chains bonded by ionic bonds. The chain structure can be fol-
Fig. 8 The optical images of scratches under different normal loads (up: silica substrate, down: $10 \mathrm{wt} \%$ nanomaterials on the silica substrate)
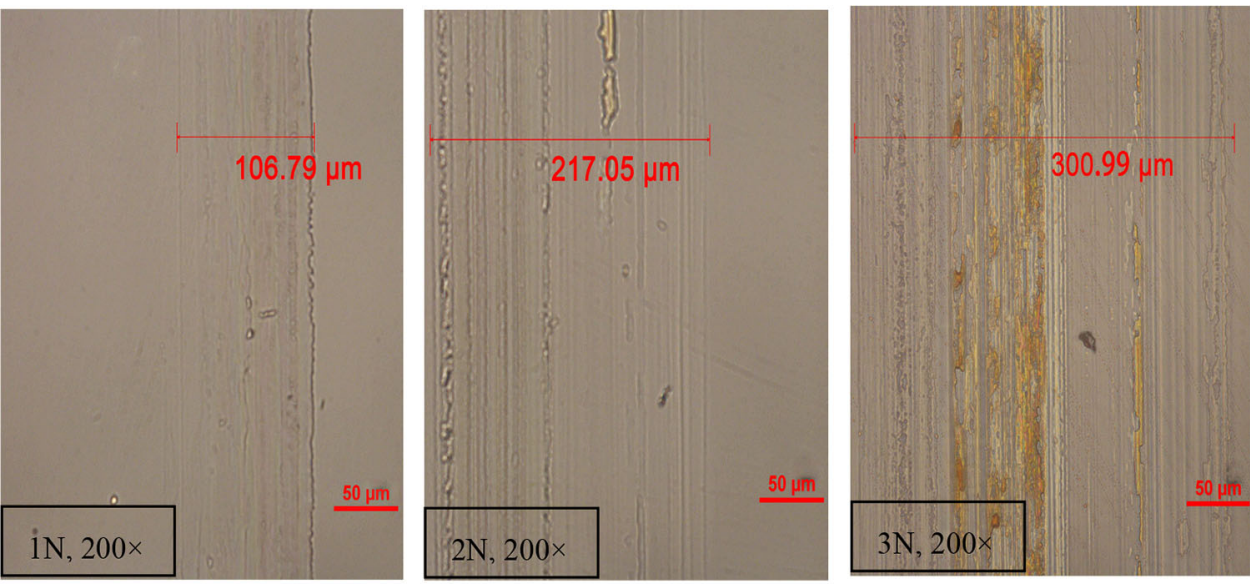

up
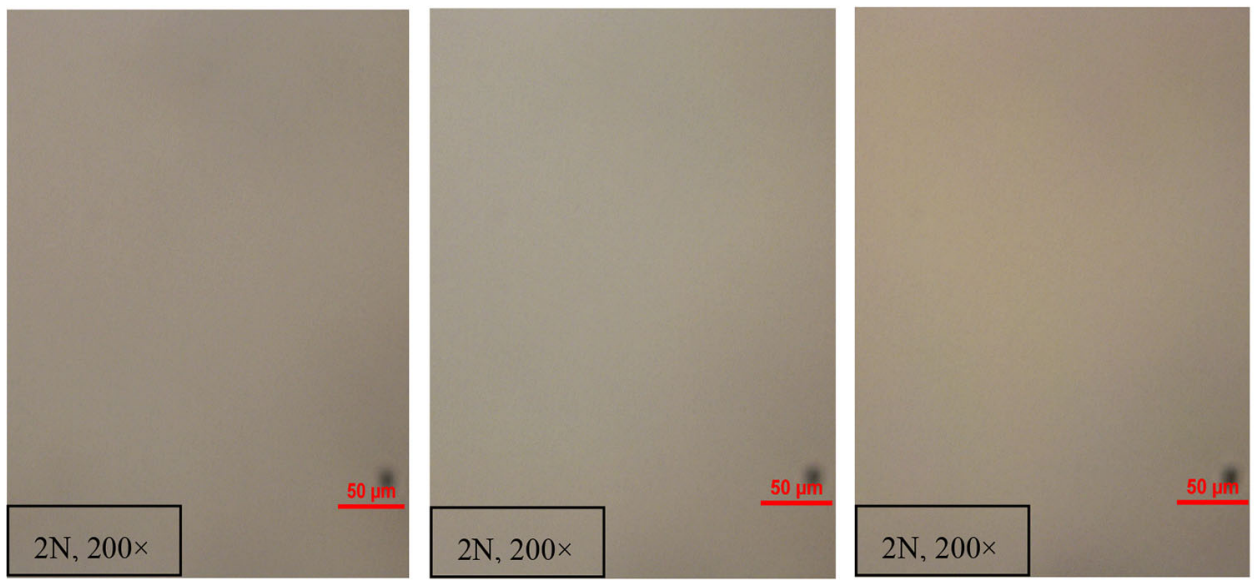

down 

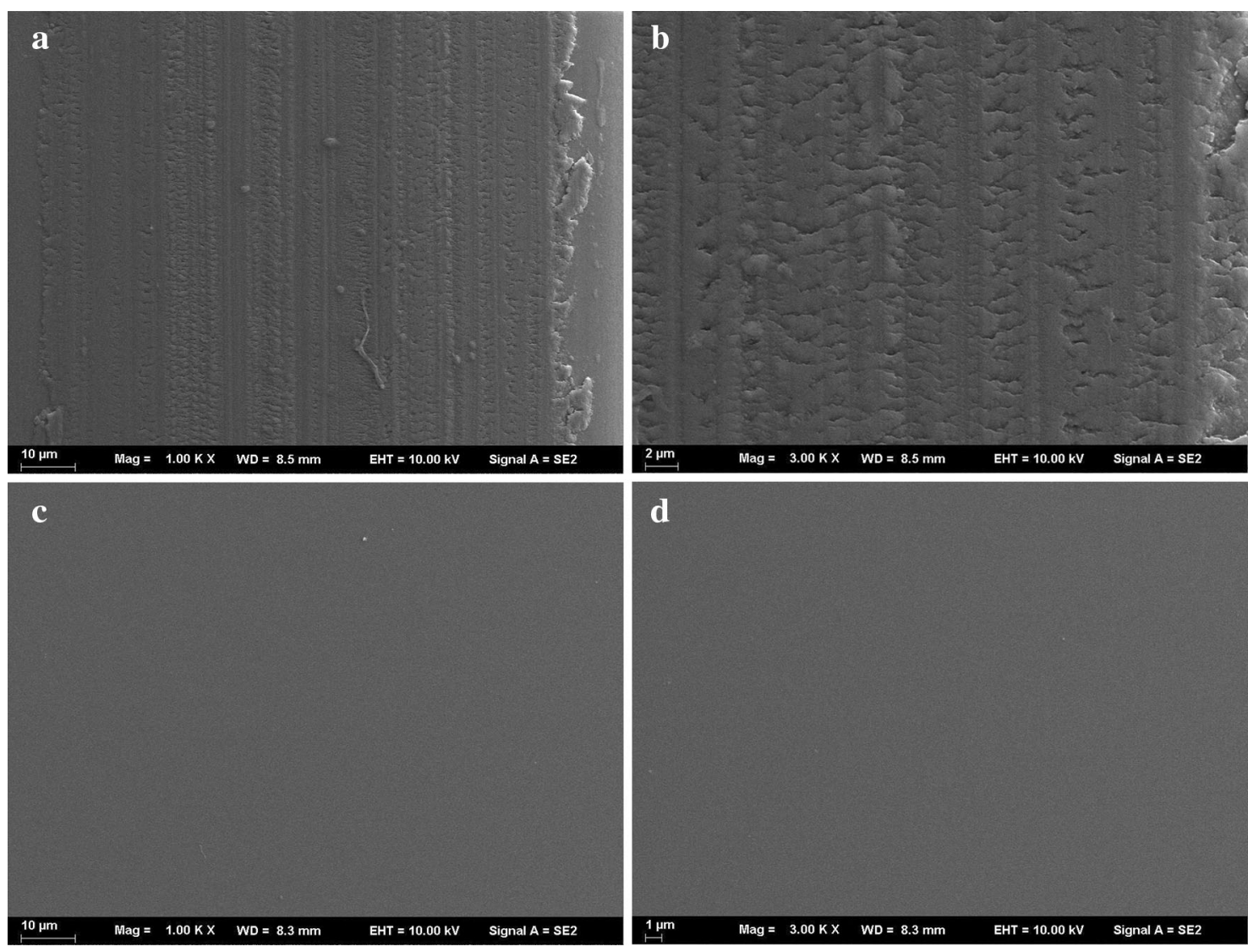

Fig. 9 SEM micrographs of scratches under $2 \mathrm{~N}$ load of silica substrate without nanomaterials (a, b) and silica substrate with 10 wt\% nanomaterials $(\mathbf{c}, \mathbf{d})$

Fig. 10 The mechanism of the self-suspended hairy $\mathrm{TiO}_{2}$ nanomaterials (left: under small load, the film is not damaged; right: the film rupture under heavy load)
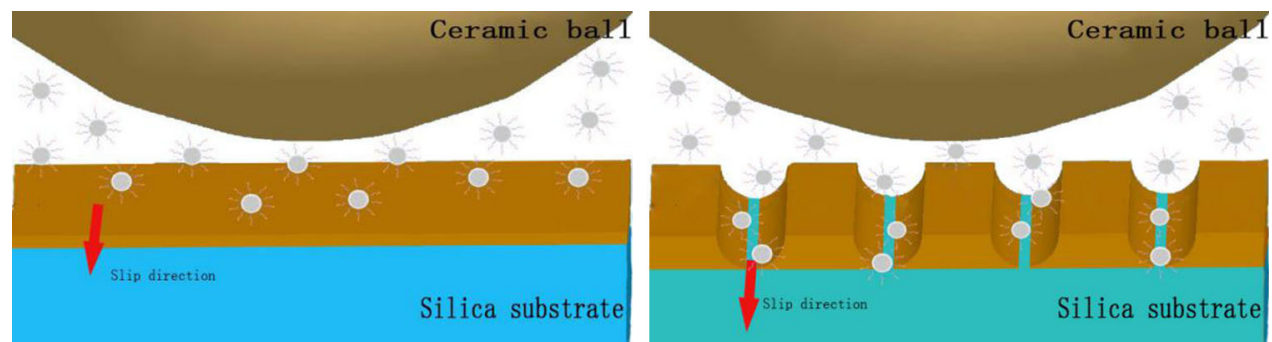

ded and compressed at will. Therefore, the carrying capacity and elasticity of the hairy ball can be increased. When the applied load is low, the lubricating film does not rupture. When the load increases, the lubricant film breaks easily. It is notable that the self-suspended hairy $\mathrm{TiO}_{2}$ nanomaterials can flow to repair damaged lubricating films (see Fig. 10). The monodispersed nanoparticles play a strengthening role on the surface of the substrate for good self-lubricating effect, which is the main bearing structure to improve wear resistance. Selfsuspended hairy nanomaterials exhibit good flexibility, strong adhesion to the substrate and can form viscous thin films, which can self-heal on the surface of the scratches and thus reduce the wear of the substrate.

\section{Materials and methods}

\section{Materials}

$\mathrm{N}$-methyl-2-pyrrolidone, methanol, ethanol, $\mathrm{HCl}$, ammonia, $n$-hexane, ethyl acetate and tetrahydrofuran were purchased from Fuchen Chemical Ind., Ltd., 3-(trimethoxysilyl) propyl chloride (industrial grade, purity 99\%) was provided by Wanda Chemical Ind. Ltd., and tetra- $n$-butyl titanate was obtained from TianJing $\mathrm{Ke}$ Miou Chemical Company. Deionized water was made in our laboratory. $\mathrm{C}_{9} \mathrm{H}_{19}-\mathrm{C}_{6} \mathrm{H}_{4}-$ $\left(\mathrm{OCH}_{2} \mathrm{CH}_{2}\right)_{20}\left(\mathrm{CH}_{2}\right)_{3} \mathrm{SO}^{3-} \mathrm{K}^{+}$was from Sigma-Aldrich. Unless otherwise stated, all solvents were of analytical grade. 


\section{Preparation of nanoparticles}

$\mathrm{TiO}_{2}$ nanoparticles were prepared by sol-gel method in the experiment. Solution A was got by mixing $17 \mathrm{~mL}$ butyl titanate with $15 \mathrm{~mL}$ anhydrous ethanol for $15 \mathrm{~min}$. Solution $\mathrm{B}$ was got by mixing and stirring $2.15 \mathrm{~mL}$ anhydrous ethanol, $2 \mathrm{~mL}(5.5 \mathrm{~mol} / \mathrm{L})$ hydrochloric acid and $1 \mathrm{~mL}$ distilled water for $10 \mathrm{~min}$. Solution B was added slowly dropwise into solution $\mathrm{A}$ and formed a gel, followed by aging for $6 \mathrm{~h}$. Next, the product was dried under $70{ }^{\circ} \mathrm{C}$ and ground carefully. Finally, we got $\mathrm{TiO}_{2}$ nanoparticles powder.

\section{Preparation of $\mathrm{TiO}_{2}$ ionic nanomaterial}

$0.5 \mathrm{~g} \mathrm{TiO}_{2}$ powder was dispersed ultrasonically for $30 \mathrm{~min}$ in $10 \mathrm{~mL}$ ammonia methanol solution $(\mathrm{pH}=10)$, then an appropriate amount of (25 wt\% methanol solution) taskspecific ionic liquids $\left[\left(\mathrm{CH}_{3} \mathrm{O}\right)_{3} \mathrm{Si}\left(\mathrm{CH}_{2}\right)_{3}\left(\mathrm{C}_{5} \mathrm{H}_{9} \mathrm{NO}\right)\right]^{+} \mathrm{Cl}^{-}$ were added into flask and stirred for $7 \mathrm{~h}$ under refluxing. The $\left[\left(\mathrm{CH}_{3} \mathrm{O}\right)_{3} \mathrm{Si}\left(\mathrm{CH}_{2}\right)_{3}\left(\mathrm{C}_{5} \mathrm{H}_{9} \mathrm{NO}\right)\right]^{+} \mathrm{Cl}^{-}$was synthesized according to the process in literature (Zhang et al. 2011). The product was washed three times with methanol and dried at $65{ }^{\circ} \mathrm{C}$. The dried product was dissolved in tetrahydrofuran and left for $5 \mathrm{~min}$. The upper suspension was separated and dried at $65{ }^{\circ} \mathrm{C} .1 \mathrm{~g}$ dried product was added into $15 \mathrm{~mL}$ (16.5 wt/vol) $\mathrm{C}_{9} \mathrm{H}_{19}-\mathrm{C}_{6} \mathrm{H}_{4}-\left(\mathrm{OCH}_{2}\right.$ $\left.\mathrm{CH}_{2}\right)_{20}\left(\mathrm{CH}_{2}\right)_{3} \mathrm{SO}^{3-} \mathrm{K}^{+}$methanol solution and reacted for $24 \mathrm{~h}$ at $70{ }^{\circ} \mathrm{C}$. The product was extracted with hot toluene for two or three times and dried at $65^{\circ} \mathrm{C}$. It was re-dispersed in $15 \mathrm{~mL}$ deionized water and extracted with hot toluene for two or three times and dried at $65{ }^{\circ} \mathrm{C}$. The dried product was dispersed in acetone, centrifuged and dried at $65{ }^{\circ} \mathrm{C}$. We finally got self-suspended hairy $\mathrm{TiO}_{2}$ nanomaterials.

\section{Characterization}

The chemical composition information about the $\mathrm{TiO}_{2}$ nanomaterials was obtained by Fourier transform infrared spectrometer WQF2310 of Beijing Second Optical Instrument Company. Thermogravimetric analysis (TGA) was performed under $\mathrm{N}_{2}$ with a TGAQ50 at a heating rate of $20{ }^{\circ} \mathrm{C}$. Differential scanning calorimetry (DSC) curves were measured using a Q1000 TA Instruments at a heating rate of $10{ }^{\circ} \mathrm{C} / \mathrm{min}$. The microstructure morphology was observed by H-800 transmission electron microscope (TEM) at an accelerating voltage of $100 \mathrm{kV}$. The microstructure of scratches was observed by Merlin Compact field emission scanning electron microscope (SEM) of Zeiss Enterprise. For this study, a few drops of an aqueous dispersion of self-suspended hairy $\mathrm{TiO}_{2}$ nanomaterials were dropped on a copper grid and the solvent evaporated prior to observation. The rheological behavior of $\mathrm{TiO}_{2}$ nanomaterials was studied using an ARG2 rheometer. A parallel plate with $40.00 \mathrm{~mm}$ diameter was used as a holder and the plate spacing was $1.00 \mathrm{~mm}$. The testing temperature range was $20-80{ }^{\circ} \mathrm{C}$. Self-healing abrasion properties of ionic nanomaterials were tested on the UMT-two friction and wear tester. The friction pattern is the ball-disc linear friction. The friction head is $\mathrm{A}_{2} \mathrm{O}_{3}$ ceramic ball, the load is $1 \mathrm{~N}, 2 \mathrm{~N}$ and $3 \mathrm{~N}$, the relative sliding speed is $25 \mathrm{~mm} / \mathrm{s}$, and the friction time is $30 \mathrm{~min}$. The images of the scratches were observed by an LV100POL polarizing microscope after removal of coated films on silicon substrates.

\section{Conclusions}

In summary, we report on synthesized ionic liquid $\mathrm{N}$-(silicon propyl trimethoxy)- $\mathrm{N}$-methyl-2-pyrrolidone hydrochloride covalently grafted on the surface of $\mathrm{TiO}_{2}$ nanoparticles. Then, monodispersed ionic nanomaterial was obtained after grafting nonylphenol polyoxyethylene ether sulfonates on the outermost layer through ion exchange. $\mathrm{TiO}_{2}$ ionic nanomaterial is a homogeneous fluid without solvent at room temperature. The surface functionalization offers novel exciting properties to $\mathrm{TiO}_{2}$ nanoparticles. The ionic nanomaterials display lower and more stable friction coefficient and exhibit outstanding self-healing lubricating behaviors, which make them ideal candidates for new lubricants for micro-electromechanic and nano-electromechanic systems (MEMS and NEMS).

\section{Supplementary materials}

The following are available online at www.mdpi.com/link, Fig. S1: The interaction mechanism of tailor-making ionic liquids and $\mathrm{TiO}_{2}$.

Acknowledgements We greatly acknowledge the National Natural Science Foundation of China (Nos. 51402132 and 21404045), Jiangsu Provincial Natural Science Foundation of China (Nos. BK20150466 and BK20140505), Six Talent Peaks Project in Jiangsu Province (No. 2015-XCL-028) and A Project Funded by the Priority Academic Program Development of Jiangsu Higher Education Institutions (PAPD). We also greatly thank a project funded by the Priority Academic Program Development of Jiangsu Higher Education Institution and the Key Laboratory funded by Jiangsu Advanced Welding Technology.

Open Access This article is distributed under the terms of the Creative Commons Attribution 4.0 International License (http:// creativecommons.org/licenses/by/4.0/), which permits unrestricted use, distribution, and reproduction in any medium, provided you give appropriate credit to the original author(s) and the source, provide a 
link to the Creative Commons license, and indicate if changes were made.

\section{References}

Arkles B (1977) Tailoring Surfaces with Silanes. Chemtech 7:766-778

Bai H, Zheng Y, Yang R (2016) Recyclable liquid-like poss derivatives with designed structures and their potential for $\mathrm{CO}_{2}$ capture. Mater Des 99:145-154

Giordani S, Bergin SD, Nicolosi V, Lebedkin S, Kappes MM, Blau WJ, Coleman JN (2006) Debundling of single-walled nanotubes by dilution: observation of large populations of individual nanotubes in amide solvent dispersions. J Phys Chem B 110:15708-15718

Gu S, Zhang Y, Yan B (2013) Solvent-free ionic molybdenum disulfide $\left(\mathrm{MoS}_{2}\right)$ nanofluids with self-healing lubricating behaviors. Mater Lett 97:169-172

Guo Z, Pereira T, Choi O, Wang Y, Hahn HT (2006) Surface functionalized alumina nanoparticle filled polymeric nanocomposites with enhanced mechanical properties. J Mater Chem 16(27):2800-2808

Guo Z, Shin K, Karki AB, Young DP, Kaner RB, Hahn HT (2009) Fabrication and characterization of iron oxide nanoparticles filled polypyrrole nanocomposites. J Nanopart Res 11(6): 1441-1452

Huang LX, Ding YX (1999) Study on the process technology and property of the trilaminated pom composites with steel basis. Acta Mater Compos Sinica 16(3):30-33

Huang J, Wang M, Wang S, Wang T, Li Q, Dong LJ, Xiong CX (2016) Self-suspended polyaniline containing self-dissolved lyotropic liquid crystal with electrical conductivity. J Polym Sci Part A Polym Chem 54(22):3578-3582

Hussein MA, Mohammed AS, Al-Aqeeli N (2015) Wear characteristics of metallic biomaterials. A Rev Mater 8:2749-2768

Kim D, Archer LA (2011) Nanoscale organic-inorganic hybrid lubricants. Langmuir 27:3083-3094

Langford SJ, Stoddart JF (1996) Self-assembly in chemical synthesis. Supramol Chem 6(1-2):11-27

Lei Y, Xiong C, Guo H, Yao J, Dong L, Su X (2008) Controlled viscoelastic carbon nanotube fluids. $\mathrm{J}$ Am Chem Soc 130:3256-3257

Li Q, Dong L, Deng W, Zhu Q, Liu Y, Xiong C (2009) Solvent-free fluids based on rhombohedral nanoparticles of calcium carbonate. J Am Chem Soc 131:9148-9149

Li Q, Dong L, Li L, Su X, Xie H, Xiong C (2012) The effect of the addition of carbon nanotube fluids to a polymeric matrix to produce simultaneous reinforcement and plasticization. Carbon 50(5):2056-2060

Li HR, Jiang M, Hu DB, Yan Y, Li Q, Dong LJ, Xiong CX (2015) Solvent-free zirconia nanofluids/silica single-layer multifunctional hybrid coatings. Colloids Surf A Physicochem Eng Asp 464:26-32

Li PP, Zheng YP, Li MZ, Fan WD, Shi T, Wang YD, Zhang AB, Wang JS (2016a) Enhanced flame-retardant property of epoxy composites filled with solvent-free and liquid-like graphene organic hybrid material decorated by zinc hydroxystannate boxes. Compos Part A Appl Sci Manuf 81:172-181

Li PP, Zheng YP, Shi T, Wang YD, Li MZ, Chen C, Zhang JX (2016b) A solvent-free graphene oxide nanoribbon colloid as filler phase for epoxy-matrix composites with enhanced mechanical, thermal and tribological performance. Carbon 96:40-48
Petit C, Lin KYA, Park AHA (2013) Design and characterization of liquid like POSS-based hybrid nanomaterials synthesized via ionic bonding and their interactions with $\mathrm{CO}_{2}$. Langmuir 29:12234-12242

Philp D, Stoddart JF (1996) Self-assembly in natural and unnatural systems. Angew Chem Int Edit 35(11):1154-1196

Rojas JP, Sevilla GAT, Alfaraj N, Ghoneim M, Kutbee AT, Sridharan A, Hussain MM (2015) Nonplanar nanoscale fin field effect transistors on textile, paper, wood, stone, and vinyl via soft material-enabled double-transfer printing. ACS Nano 9(5):5255-5263

Tan Y (2013) Property-structure relationship of titania ionic liquid nanofluids. Soft Mater 11:315-320

Tang Z, Zhang L, Zeng C, Lin T, Guo B (2012) General route to graphene with liquid-like behavior by non-covalent modification. Soft Matter 8:9214-9220

Tang J, Zhou H, Liang Y, Shi X, Yang X, Zhang J (2014) Properties of graphene oxide/epoxy resin composites. J Nanomater 2014:696859

Wang G (2008) Principles of polymer molding and processing. Chemical Industry Press, Beijing

Warren SC, Banholzer MJ, Slaughter LS, Giannelis EP, DiSalvo FJ, Wiesner UB (2006) Generalized route to metal nanoparticles with liquid behavior. J Am Chem Soc 128:12074-12075

Yang RL, Zheng YP, Li PP, Wang YD, Bai HP, Chen LX (2016a) Investigation of power strip like composite nanoparticles derivative with liquid-like behaviour on capturing carbon dioxide. New J Chem 41(2):603-610

Yang HX, Liu XY, Sun SN, Nie Y, Wu HP, Yang TY, Zheng SJ, Lin SL (2016b) Green and facile synthesis of graphene nanosheets/ $\mathrm{K}_{3} \mathrm{PW}_{12} \mathrm{O}_{40}$ nanocomposites with enhanced photocatalytic activities. Mater Res Bull 78:112-118

Yang SW, Tan YQ, Yin XZ, Chen SH, Chen DZ, Wang LX, Zhou YS, Xiong CX (2016c) Preparation and characterization of monodisperse solvent-free silica nanofluids. J Dispersion Sci Technol 38:425-431

Ye C, Liu W, Chen Y, Yu L (2001) Room-temperature ionic liquids: a novel versatile lubricant. Chem Commun 21:2244-2245

Yu HL, Liu J, Qiu S, Cao Y, Hu C, Guo S et al (2016) Carbon composite spun fibers with in situ formed multicomponent nanoparticles for enhanced performance lithium-ion battery anode. J Mater Chem A 4(25):9881-9889

Zhang J, Zheng Y, Yu P, Mo S, Wang R (2009a) The synthesis of functionalized carbon nanotubes by hyperbranched poly(amineester) with liquid-like behavior at room temperature. Polymer 50:2953-2957

Zhang JX, Zheng YP, Yu PY, Mo S, Wang RM (2009b) Modified carbon nanotubes with liquid-like behavior at $45^{\circ} \mathrm{C}$. Carbon 47:2776-2781

Zhang J, Zheng Y, Lan L, Yu P, Shi W, Li J, Tan Y (2011) Synthesis and characterization of task specific ionic liquid $\mathrm{N}$ (trimethoxysilyl)propyl- $N$-methyl-2-pyrrolidone chlorides with surface activities. Chin J Org Chem 31:1076-1080

Zhang JX, Jang KM, Zheng YP, Wu F, Li YQ (2013) The preparation of solvent-free multiwall carbon nanotubes/silica hybrid nanomaterial with liquid-like behavior. Funct Mater Lett 6(2):6350015

Zheng D, Cai ZB, Shen MX, Li ZY, Zhu MH (2016) Investigation of the tribology behaviour of the graphene nanosheets as oil additives on textured alloy cast iron surface. Appl Surf Sci 387:66-75

\section{Publisher's Note}

Springer Nature remains neutral with regard to jurisdictional claims in published maps and institutional affiliations. 